\title{
EXPERIMENTAL DEVELOPMENT OF A FOCALIZATION MECHANISM IN AN INTEGRATED NARRATIVE GENERATION SYSTEM
}

\author{
Taisuke Akimoto $^{1}$, Takashi Ogata ${ }^{2}$ \\ ${ }^{1}$ Graduate School of Informatics and Engineering, the University of Electro-Communications, \\ 1-5-1 Chofugaoka, Chofu, Tokyo 182-8585, Japan \\ ${ }^{2}$ Faculty of Software and Information Science, Iwate Prefectural University, \\ 152-52, Sugo, Takizawa, Iwate 020-0693, Japan
}

\begin{abstract}
"Focalization" is a narrative discourse technique that produces different narrative structures based on choosing unique perspectives from which to present a story. This study designs a focalization mechanism and presents an experimental implementation. The proposed system functions as part of our integrated narrative generation system (INGS). In addition, the approach computationally extends the conceptual research of focalization by Genette to techniques for narrative generation. We define focalization as a procedure to transform a story structure into discourse structures through the following two steps: 1) restricting the scope of story information perceived from a chosen perspective, and 2) generating a discourse structure based on perceived story information. In particular, we define two types of rules for restricting the perception scope based on: a) objective perceptible possibility of constituent elements in a story and b) situations or states in which constituent elements in a story are positioned. Based on the experimentally implemented system, we present generated examples from a story using different focalization types. Through analysis, we show that the basic function of the focalization mechanism was achieved by the aforementioned rules.
\end{abstract}

\section{Introduction}

A variety of narratives can be produced from a "story," that is, the content plane of a narrative, based on narrative "discourse" processing, which basically refers to the structural aspect of how a story is expressed. This study deals with the issue of "focalization" in narrative discourse from the standpoint of our narrative generation system. Focalization is a narrative discourse technique that produces different narrative structures based on choosing specific perspectives from which to present a story. Focalization techniques are crucial for actual narrative construction. For instance, when telling a story of a war between two sides, the teller can describe one side as an "enemy" or as "evil" by placing the perspective on the opposite side. Narrative works exist that are characterized by the contradiction caused by presenting a story from multiple perspectives. Examples include "Yabu no Naka" ("In a Grove") (1922) by R. Akutagawa and "Rashomon" (1950) by A. Kurosawa. In addition, focalization and computational modeling will, more generally, contribute to the study of human-computer interaction as a model for considering the temporal and spatial situation of humans.

This study designs a focalization mechanism and presents an experimental implementation. The 
proposed system operates as part of our integrated narrative generation system (INGS) $[1,2,3]$, which is a relatively large-scale system in which we organically synthesize a variety of theories, methods, and knowledge from our previous narrative generation study. Ogata [1] presented the background concepts and basic design based on previous narrative generation methods and systems [1,3] in order to start an experimental but comprehensive implementation. The study in [2] reported on the system's developmental status in 2012 and later [3] revealed the 2014 version of the integrated architecture in which most of the basic components were implemented. Story and discourse generation are clearly differentiated in the architecture of INGS and a group of focalization techniques is used as a technique of structural transformation from a story structure to discourse structures. Therefore, a key distinguishing feature of our proposed system is to incorporate the focalization mechanism into other INGS components. Simultaneously, through a kind of modular approach, the focalization techniques themselves can always be integrated into INGS.

In addition, the approach computationally extends the conceptual research of focalization conducted by Genette [4], a French literary theorist, to techniques for narrative generation. We have been working on a systematic integration of narrative discourse techniques and some of the categories of discourse techniques presented by Genette have already been implemented [5, 6, 7, 8, 9]. These studies dealt with discourse techniques including "tense," "focalization," "distance," and "voice" in Genette's theory. These are part of our background concept of "expanded literary theory" $[3,10,11]$, which aims to the computational reconstruction of existing narratology and literary theories for blending with narrative generation. Although we have interpreted and systematized a variety of literary theories based on the computational viewpoint, a current goal of expanded literary theory is to incorporate various literary theories into INGS. Actually, we have used three types of narrative theories, including Genette's in INGS.

The remainder of this paper is organized as follows. Section 2 explains the literary concept of focalization, and Section 3 outlines related works in the field of artificial intelligence and narrative generation systems. Section 4 designs a focalization mechanism, while Section 5 describes the experimental implementation. Section 6 shows several examples of generated discourses and verifies the soundness of the mechanism based on an analysis of the discourses. Section 7 concludes the paper.

\section{Focalization as a literary tech- nique}

G. Genette is a French literary theorist associated mainly with structuralism. His narrative discourse theory [4] clearly categorized various classes of discourse strategies through the analysis of the novel, "À la recherche du temps perdu" ("In Search of Lost Time" or "Remembrance of Things Past") (1913-1927) by M. Proust. It consists of the following three broad categories: "tense," which concerns the relationship between the time of the story and that of the discourse; "mood," which concerns the modality for regulating narrative information; and "voice," which concerns the relationship among narration, story, and discourse. Each category is further divided into subcategories and the "focalization" is a subcategory of "mood." The technique of focalization was derived from the concept of narrative "perspective," which has been defined as "the second mode of regulating information, arising from the choice (or not) of a restrictive "point of view" [4]. Genette described the following three basic types of focalization:

- "Zero focalization" or nonfocalized narrative.

- "Internal focalization" or narrative focalized by one character's perspective. This is further divided into three variations: "fixed," "variable," and "multiple."

- "External focalization" or narrative, which presents only the external behavior of characters.

From our standpoint, focalization as a discourse technique for computational narrative generation is defined as the transformation of the whole or part of a story structure into a discourse structure based on the restricted information associated with a chosen perspective. 


\section{Related works}

Narrative generation is a challenging topic in the field of artificial intelligence. Whereas many narrative generation systems - such as TALE-SPIN by Meehan [12] and a story generation system based on Propp's "Morphology of the Folk Tale" by Gervás [13]—focus primarily on methods for generating stories, several researchers have introduced the idea of a narrative discourse that utilizes Genette's theory. Lönneker-Rodman [14] presented a conceptual design for introducing the "voice" in Genette's theory into a natural language generation system. Montfort [15] developed an interactive fiction system in which the progression of a story can be managed through natural language interaction with the user. This exchange contains a function to produce variations within the discourse. These rules are based on Genette's categorization. Jhale and Young [16] proposed a camera-work operation system for creating a discourse of visual narratives in a three-dimensional (3D) virtual environment.

In addition, several researches address the topic of focalization. Bae et al. [17] presented a system that generates different stories based on various types of planning. Such planning is based on character viewpoints toward the same events by using "multiple internal focalization." A simulation of the "Rashomon" by Kurosawa is provided as an example. Gervás [18] proposed a system that simulates narrative compositions based on "focalization" in a simplified story of a chess game. His system composes narratives from the log of a chess game, i.e., player moves of chess pieces on the board. The game $\log$ corresponds to a story and a narrative is composed based on the experience (i.e., perspective) of a particular chess piece.

We also proposed a prototype focalization system in 2004 [7]. However, it was separately constructed from the other components of narrative generation. The input story was specially prepared by hand and the system simply removed the unperceived parts of the story according to a chosen perspective. A concern of our current research is to generalize and revise the method for integration with the framework and knowledge base of INGS.

\section{Designing a focalization mecha- nism}

This section describes the design of a focalization mechanism. The first subsection describes the position of the mechanism in INGS and the second subsection describes the fundamental method of focalization.

\subsection{The position of the focalization mecha- nism in INGS}

Fig. 1 outlines the architecture of INGS. It is divided into three generation phases of story, discourse, and expression. A story represents the content information of a narrative. In particular, it represents the temporal sequence of events and their constituent elements of characters, objects, and locations. A discourse is composed by transforming a story structure. Both a story and discourse are described as conceptual representations. Surface media representations using language, visual images, and music are generated by the expressiongeneration component. The final outputs from the user's viewpoint are basically surface expressions. However, a narrative in INGS is constructed as a totality of a story, discourse, and expression. Each generation phase consists of several module types related to narrative techniques used for narrativestructure or surface-expression generation, and the control mechanism. In addition, these module types use knowledge bases that include "conceptual dictionaries," a "narrative content knowledge base," and an "event/state transformation knowledge base." The essential portions are implemented with Common Lisp programing language and, with the exception of the knowledge bases, have approximately 750 functions. More detail information on INGS was presented in our other studies; the concepts underlying the system were described by $[1,3]$, the system's overall framework was presented in [2,3], and composition of the conceptual dictionaries was described in [19].

The focalization mechanism is incorporated into the discourse generation mechanism as one of the discourse techniques. The discourse mechanism generates a discourse structure(s) by transforming a story structure into a discourse structure(s). Fig. 2 shows the structural transformation. Both structures are represented with a tree form consisting of 


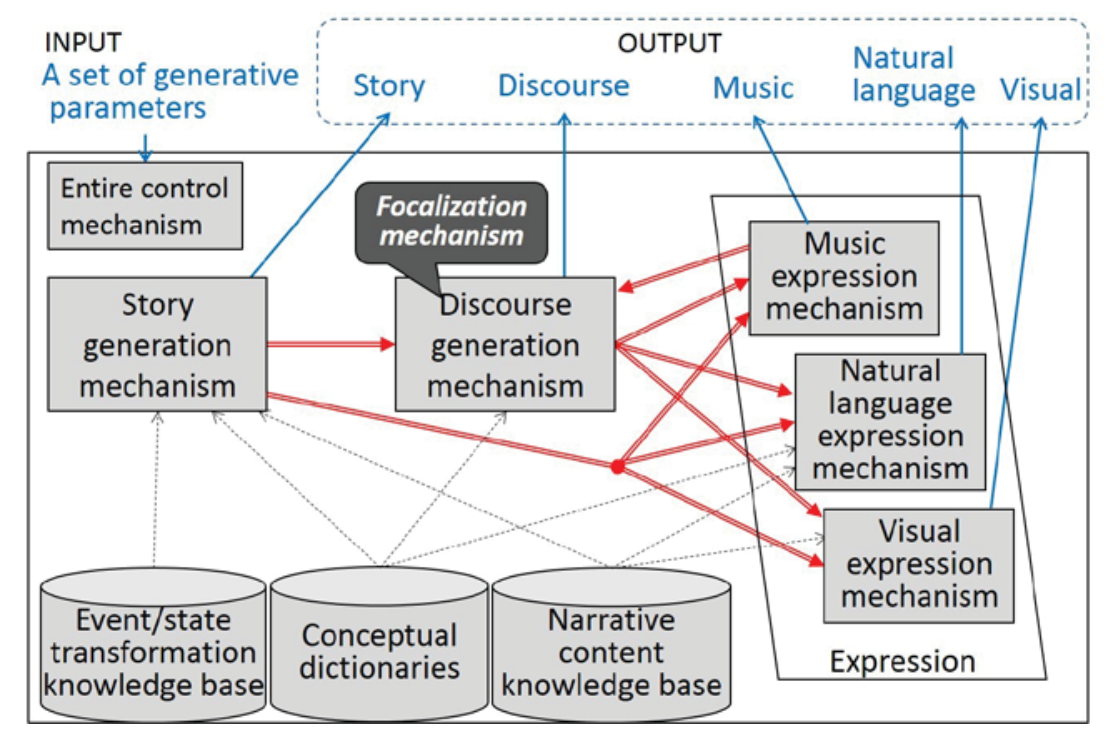

Figure 1. Architecture of INGS

events and relations, indicated by " $\mathrm{E}$ " " and " $\$ *$," respectively. An event is the basic unit of constituting a story or discourse, whereas a relation semantically combines the child nodes, i.e., the events or sub-structures.
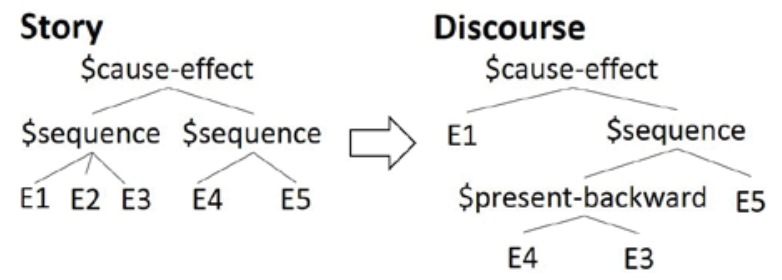

Figure 2. Transformation from a story structure to a discourse structure

We detail the constituent elements of a story based on Fig. $3^{1}$. An event is described by means of a conceptual representation form as a case structure that includes a verb concept and related instances of noun concepts. For example, the event described as "(event Eat (time (time1 time2)) (agent age\%Boy\#1) (object obj\%Apple\#1) (location loc\%House\#1))" means "a boy eats an apple in a house." Each instance corresponds to an individual character, object, or location in a story and is defined by a frame form, which consists of a set of attributes. Each attribute is represented by a slot and its value. For example, in the attribute "(name Taro)," an attribute of age\%Boy\#1 in Fig. 3, name refers to the slot name and Taro is the value. The information defining each instance is described and managed in states. A state is the static information within a story, whereas an event corresponds to the dynamic information. Each event bridges two states of the before and after states. In other words, an event causes a change in states, and the after state is equal to the before state of the next event. The chief functions of the states are to maintain the knowledge about a story's world and to manage the coherency of the flow of events. These story mechanisms are detailed in $[20,21]$.

As described previously, a story in INGS is similar to a kind of knowledge, which consists of a story's world and includes unexpressed information in a discourse. A story's information that will be actually expressed in a narrative is selected during the discourse generation phase. In particular, some events in a story will be omitted in a discourse, while information about states is selectively recounted as descriptions of external attributes of instances or explanations of abstract attributes.

\subsection{Fundamental method of focalization}

The main function of the focalization mechanism is to restrict the scope of perceived information or elements in a story according to a chosen perspective. We call this perceived information a "focalized story," which is similar to the target or source of generating discourses. However, when

\footnotetext{
${ }^{1}$ The actual data related to verb and noun concepts as well as attributes are defined and represented based on Japanese words. In this paper, we show them by English words manually translated.
} 


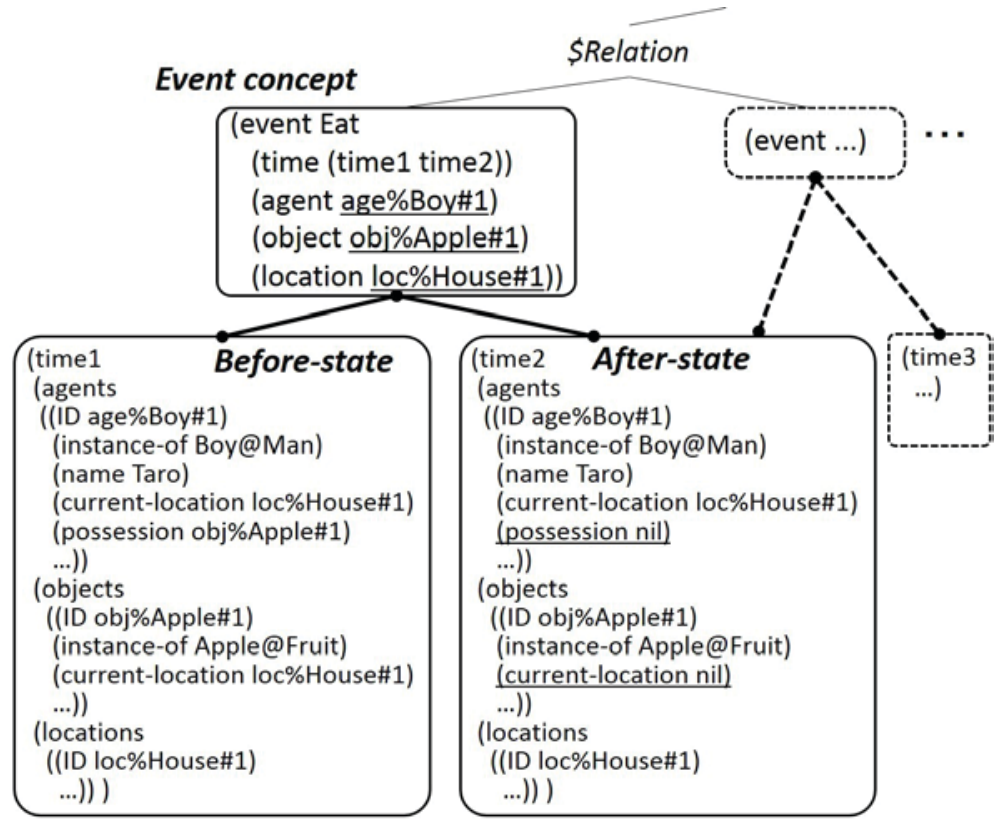

Figure 3. Structure of a story

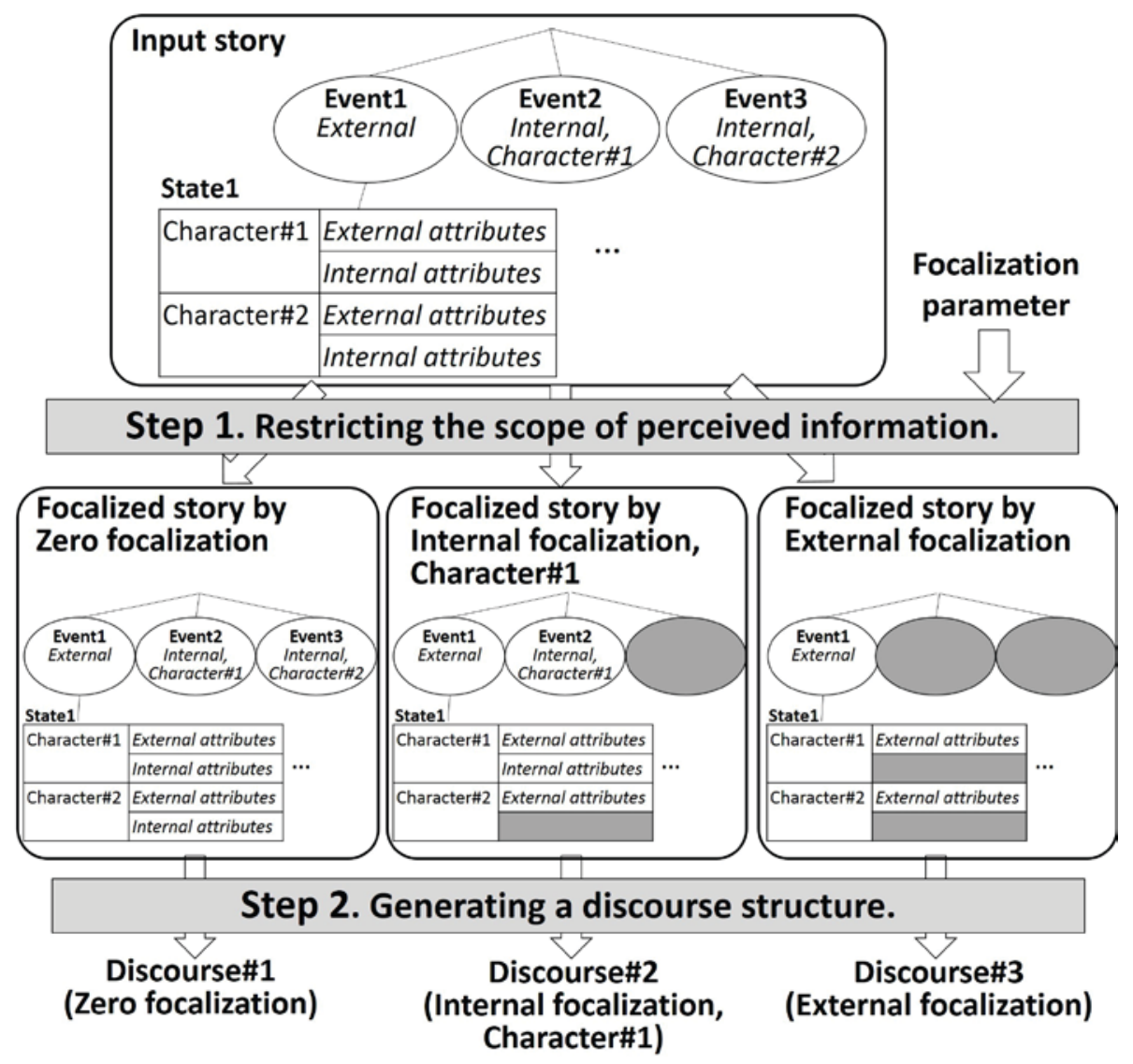

Figure 4. An outline of the focalization procedure 
combined with other discourse techniques such as temporal ordering, a variety of discourse structures can be generated from a focalized story. The focalization technique essentially acts as a story's information regulator prior to other discourse techniques.

We designed a fundamental procedure of focalization as shown in Fig. 4. The input information is a story and "focalization parameter," which indicates a type of focalization as "zero," "internal," or "external." When the type is internal, a "focalizer" instance, that is, the holder of the perspective, is additionally indicated. The procedure is divided into the following two steps. Step 1 produces the focalized story by determining unperceived elements in the story according to the given focalization parameter. Step 2 generates the discourse structure from the focalized story.

We herein describe the method of each step.

Step 1. Restricting the scope of perceived information. We assume that this task requires two types of knowledge. The first is the objective perceptible possibility of constituent elements in a story. It refers to whether the element can be perceived from a third person viewpoint by means of the five senses. The second concerns restrictions of scope that depend on situations or states in which the constituent elements in a story are positioned. Thus, Step 1 uses the following two types of rules to determine unperceived elements in a story:

a) Rules of objective perceptible possibility: These rules divide a story's constituent elements, in particular events and attributes of instances in states, into "external" and "internal" events and attributes. The external type means the elements are objectively perceptible, whereas the internal type means they are not. The internal elements are perceived only by the agent of the events or holder of the attributes. For instance, bodily activities such as eat are external and thinking activities as imagine are internal.

b) State-based restriction rules: These rules restrict the perception scope based on the state in which the focalizer and the story's elements are positioned. For instance, when the focalizer is in his house, he will not perceive events in other places such as a park. These types of rules are used by only "internal focalization."
Based on these rules, the scope of the perceived information in each focalization type is defined as follows:

- "Zero focalization": This perceives all the story's elements, i.e., it does not restrict the story's information.

- "Internal focalization": This perceives the external events and attributes, which are restricted based on state-based restriction rules, and the focalizer's internal events and attributes. This rule does not perceive internal events and attributes by instances other than those of the focalizer.

- "External focalization": This perceives all external events and attributes in a story. It does not perceive all internal events and attributes.

Step 2. Generating a discourse structure. In essence, this does not apply other discourse techniques, but constructs the discourse tree structure in which the unperceived events in the focalized story are removed.

\section{Experimental implementation}

We implemented an experimental focalization system based on the design outlined in this paper. This section provides technical explanations of the implemented system.

\subsection{Outline of the system}

The experimental system was implemented with Common Lisp and was connected with the story mechanism and natural language generation mechanism in INGS. Fig. 5 shows the system configuration. Input for this experimental system is a story generated by the story mechanism. It consists of a tree structure of events and a sequence of states. After starting the system, the user first sets a focalization parameter by choosing a type: "zero," "internal," or "external." When internal is selected, the user also selects a focalizer instance from all character instances in the story. The system then proceeds to Steps 1 and 2. Step 1 outputs the focalized story in which the unperceived elements in the input story are marked. Step 2 outputs a discourse structure by removing only the unperceived events from the focalized story. The output is connected to the 
natural language generation mechanism in INGS. The next subsection details the implemented rules for Step 1.

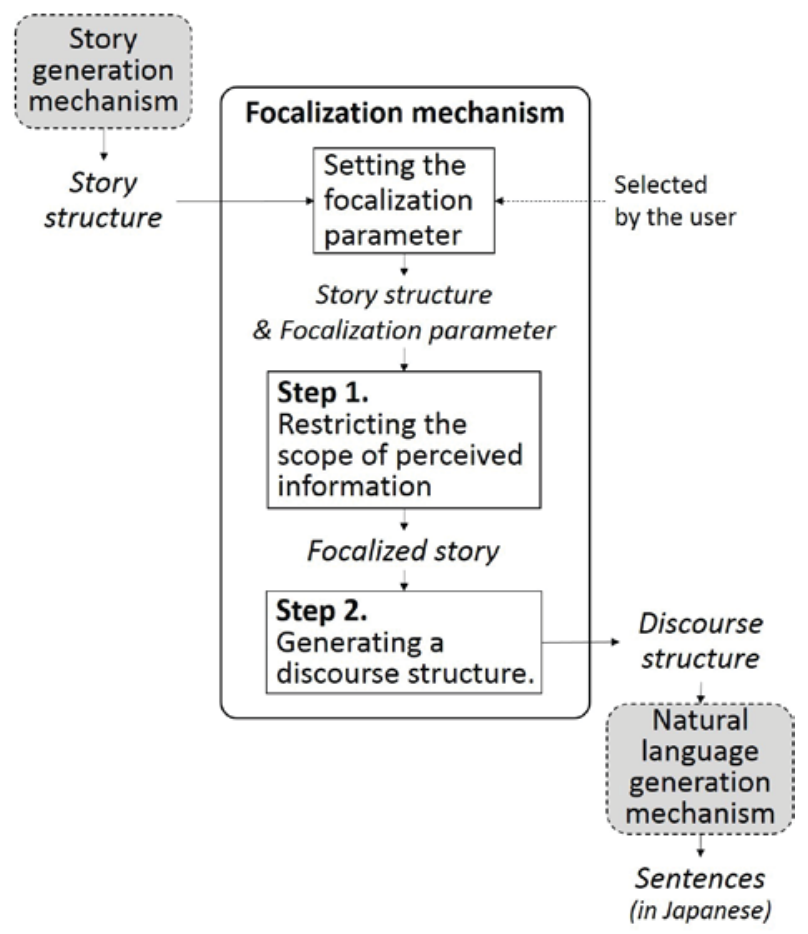

Figure 5. Configuration of the experimental system

\subsection{Implementing the rules for restricting perception scope}

The following rules were implemented for Step 1.

\subsubsection{Divisions of story elements based on ob- jective perceptible possibility}

The rules of objective perceptible possibility were defined based on the divisions of each verb concept and attribute slot into "external" and "internal" types.

We assumed that the objective perceptible possibility of an event is dependent on the category of verb concepts. The verb conceptual dictionary in INGS contains 11,951 verb concepts in 36 categories such as body-motion and thinking-action. We divided the categories into external and internal types as shown in Table 1 (Rule I-1) according to the following procedure. First, we sampled 20 verb concepts at random from each category. When the category contained less than 20 verb concepts, all verb concepts were sampled. The total number of sampled verb concepts was 584. Second, we divided the verb concepts into external and internal types based on whether events described by the verb concept were objectively perceptible. Third, although most of the categories contained both types, we assigned the type of each category to the side containing the majority of samples. In Table 1, the number in parenthesis after each category refers to the ratio of the number of external verb concepts to the number of samples. In addition, the hyphen ("'-") in parenthesis means that the category has no verb concepts. Therefore, we placed it in the external side.

Table 1. Divisions of categories of verb concepts (Rule I-1)

\begin{tabular}{|l|l|}
\hline External verb concepts & Internal verb concepts \\
\hline \hline event $(-)$ & attribute $(6 / 20)$ \\
state $(19 / 20)$ & relative-relationship \\
abstract-relationship & $(8 / 20)$ \\
$(1 / 1)$ & causal-relationship \\
being $(17 / 20)$ & $(6 / 20)$ \\
ownership $(15 / 20)$ & sensory-state $(6 / 17)$ \\
mental-relationship (2/2) & emotional-state $(1 / 20)$ \\
natural-phenomenon & thinking-state $(0 / 18)$ \\
(20/20) & thinking-action $(9 / 20)$ \\
action $(16 / 20)$ & mental-state $(3 / 8)$ \\
physical-action $(1 / 1)$ & physical-state $(5 / 11)$ \\
physical-transfer $(20 / 20)$ & emotional-action $(6 / 20)$ \\
possessive-transfer & possible $(1 / 10)$ \\
$(20 / 20)$ & \\
change-of-attribute & \\
$(17 / 20)$ & \\
change-of-body $(18 / 20)$ & \\
result $(18 / 20)$ & \\
body-motion $(20 / 20)$ & \\
utilization $(19 / 20)$ & \\
combining-action & \\
$(18 / 20)$ & \\
generation $(19 / 20)$ & \\
demise/destruction & \\
$(19 / 20)$ & \\
mental-action $(-)$ & \\
mental-transfer $(20 / 20)$ & \\
sensory-action $(13 / 20)$ & \\
causative $(16 / 16)$ & \\
begin $(19 / 20)$ & \\
close $(19 / 20)$ & \\
\hline
\end{tabular}


Meanwhile, 37 types of attribute slots, such as location, consciousness, exterior, and behavioralobjective, are used in the current version of INGS for representing instances and states. We divided the attribute slots into external and internal types (see Table 2, Rule I-2). The basis of the division was whether the attribute is objectively perceptible.

Table 2. Division of the attribute slots (Rule I-2)

\begin{tabular}{|l|l|}
\hline External attribute slots & Internal attribute slots \\
\hline \hline location & ID \\
possession & instance-of \\
health & type \\
posture & name \\
exterior & job \\
exterior-equipment & affiliation \\
clothes & behavioral-objective \\
consciousness & social-relationship \\
position & address \\
humidity & words \\
size & perception \\
temperature & memory \\
light & ability \\
figure & durability \\
open/close & \\
color & \\
length & \\
material & \\
height & \\
in/out & \\
has & \\
in & \\
distance & \\
\hline
\end{tabular}

\subsubsection{State-based restriction rules}

Second, although modeling the relationship between the states and perception scope includes complex issues, we started by defining a few simplified rules. We implemented the four rules as shown in Fig. 6 (Rules II-1 and II-2), which are conditioned by the focalizer's two attributes of location (i.e., the place in which the instance exists) and consciousness (i.e., the state of consciousness such as waking, sleeping, fainting, etc.)

\section{II-1. For events:}

a) consciousness: When the focalizer loses consciousness, no events are perceived.

b) location: Events occurring different locations from the focalizer's location are not perceived.

II-2. For attributes of instances:

c) consciousness: When the focalizer loses consciousness, no attributes of instances are perceived.

d) location: The attributes of instances in different locations from the focalizer's location are not perceived.

Figure 6. The state-based restriction rules (II-1 and II-2)

\subsubsection{Procedure for applying rules}

1 Obtaining the first event $\rightarrow E$.

2 Obtaining the before-state of $E \rightarrow S$.

3 When the focalization type is "internal," obtaining the focalizer's attributes of consciousness and location from $S$.

4 Discriminating whether $E$ is perceived based on the focalization parameter and Rules I-1 \& II-1.

5 Discriminating whether each attribute of all instances in $S$ is perceived based on the focalization parameter and Rules I-2 \& II-2.

6 If $E$ is the final event of the story, going to Line 7. Otherwise, obtaining the next event $\rightarrow E$ and going to Line 2 .

7 Obtaining the final state $\rightarrow S$.

8 Conducting the same processing with Line 5 .

9 Finishing the process by returning the focalized story.

$$
\text { (" } \rightarrow \text { " means setting the variable value) }
$$

Figure 7. Process flow of Step 1

Fig. 7 defines the process flow for applying the aforementioned rules to an input story in Step 1. The mechanism obtains each event and its before state in order from the front (Lines 1, 2, and 
6), and then marks the unperceived elements based on the focalization parameter and aforementioned rules (Lines 3 to 5). Because the final state has no posterior event, the final state is processed in Lines 7 and 8.

\section{Generation examples}

This section presents several examples of discourses generated from an input story. While an actual input story and output discourse are conceptual representations (see Section 4.1), we show the following examples using sentences. Each example is an English translation of Japanese text generated from the conceptual representation of the story or discourse using the natural language generation mechanism in INGS. Fig. 8 shows the input story generated by the story mechanism. This is a relatively short and simple story about a prison break; the characters in the story are a prisoner and prison guard. Table 3 summarizes states at key moments in the story.

\section{Input story}

E1) A prisoner worked in a prison. E2) A prison guard beat the prisoner. E3) The prison guard cursed the prisoner. E4) The prison guard beat the prisoner. E5) The prison guard kicked the prisoner. E6) The prisoner got angry at the prison guard. E7) The prison guard got pleasure. E8) The prisoner planned a prison breaking. E9) The prison guard slept. E10) The prisoner dug a hole for getting away. E11) The prisoner broke out of the prison. E12) The prisoner went to a forest from the prison. E13) The prison guard wakened. E14) The prisoner rested at the forest. E15) The prison guard went to the forest from the prison. E16) The prisoner escaped from the forest.

Figure 8. English version of the input story
Table 3. Summaries of the states at key moments in the story

\begin{tabular}{|l|l|}
\hline time & Summary \\
\hline \hline $\begin{array}{l}\text { S1 } \\
\text { the initial state) }\end{array}$ & $\begin{array}{l}\text { The prisoner and prison } \\
\text { guard are in the prison. }\end{array}$ \\
\hline $\begin{array}{l}\text { S10 } \\
\text { (after E9) }\end{array}$ & $\begin{array}{l}\text { The prisoner and prison } \\
\text { guard are in the prison. } \\
\text { The prison guard is sleeping. }\end{array}$ \\
\hline $\begin{array}{l}\text { S13 } \\
\text { (after E12) }\end{array}$ & $\begin{array}{l}\text { The prisoner is in the forest. } \\
\text { The prison guard is sleeping } \\
\text { in the prison. }\end{array}$ \\
\hline $\begin{array}{l}\text { S14 } \\
\text { (after E13) }\end{array}$ & $\begin{array}{l}\text { The prisoner is in the forest. } \\
\text { The prison guard is waking in } \\
\text { the prison. }\end{array}$ \\
\hline $\begin{array}{l}\text { S16 } \\
\text { (after E15) }\end{array}$ & $\begin{array}{l}\text { The prisoner and prison } \\
\text { guard are in the forest. }\end{array}$ \\
\hline
\end{tabular}

D2

E1) A prisoner worked in a prison. E2) A prison guard beat the prisoner. E3) The prisen guard cursed the prisor. E4) The prison guard beat the prisoner. E5) The prison guard kicked the prisoner. E6) The prisoner got angry at the prison guard. E7) The prisen prard pleasure. E8) The prisoner planned a prison breaking. E9) The prison guard slept. E10) The prisoner dug a hole for getting away. E11) The prisoner broke out of the prison. E12) The prisoner went to a forest from the prison. E13) The prison guard wakened. E14) The prisoner rested at the forest. E15) The prisen guard went to the forest from the prison. E16) The prisoner escaped from the forest.

Figure 9. English version of the discourse by internal focalization based on the prisoner

We executed the system by inputting the story and each of the following four focalization parameters: D1) "zero," D2) "internal" by the prisoner, D3) "internal" by the prison guard, and D4) "external." Because "zero" focalization does not limit the story's information, the result of D1 was unchanged from the input story. Fig. 9-11 show English translations of the results of D2-D4, respectively. The sentences containing strike-through marks indicate removed events from the story. Although the system determines unperceived elements in events and instance attributes in states, these discourses consist only of events. This is because the focalization mechanism does not insert state information into 
the discourse. After the focalization process, the restricted states can be used by other discourse techniques to generate descriptions and explanations of instances.

E1) A prisoner worked in a prison. E2) A prison guard beat the prisoner. E3) The prison guard cursed the prisoner. E4) The prison guard beat the prisoner. E5) The prison guard kicked the prisoner. E6) The prisener got angy at the prisen E7mard. The prison guard got pleasure. E8) The prisoner planned a prison breaking. E9) The prison guard slept. E10) The prisoner dug a hole for getting away. E11) The prisoner broke out of the prison. E12) The prisoner went to a forest from the prison. E13) The prison guard wakened. E14) The prisoner rested at the forest. E15) The prison guard went to the forest from the prison. E16) The prisoner escaped from the forest.

Figure 10. English version of the discourse by internal focalization based on the prison-guard

E1) A prisoner worked in a prison. E2) A prison guard beat the prisoner. E3) The prisen the prisoner. E4) The prison guard beat the prisoner. E5) The prison guard kicked the prisoner. E6) The prisener get angry at the prisen guard. E7) The prisen guard got pleasure. E8) The prisoner planned a prison breaking. E9) The prison guard slept. E10) The prisoner dug a hole for getting away. E11) The prisoner broke out of the prison. E12) The prisoner went to a forest from the prison. E13) The prison guard wakened. E14) The prisoner rested at the forest. E15) The prison guard went to the forest from the prison. E16) The prisoner escaped from the forest.

Figure 11. English version of the discourse by external focalization

First, we compare the discourses of internal focalization based on the prisoner (D2, Fig. 9) and prison guard (D3, Fig. 10). Four events (E3, E7, $E 13$, and E15) were removed in D2. Events E3 and E7 were deemed internal events of the prison guard based on the division of verb concepts (Rule I-1, Table 1). In addition, the state-based restriction Rule II-1b in Fig. 6 was applied to E13 and
E15 because of the difference between the location of the prisoner and that of events. As we showed in Table 3, the prisoner and prison guard are in different locations during S13-15. On the other hand, seven events (E6, E8, and E10-14) were removed in D3. Events E6 and E8 were restricted by Rule I- 1 and E14 was restricted by Rule II- $1 \mathrm{~b}$. The other four events, E10-13, were removed based on Rule II-1a because the consciousness of the prison guard is sleeping through $\mathbf{S 1 0 - 1 3 ~ ( s e e ~ T a b l e ~ 3 ) . ~ E v e n t ~}$ E13 (waken) was not perceived by the prison guard. This is because the system refers only to the before state of each event as the condition of the statebased restriction rules. Both the before and after states are required for the condition.

We next examine the result of external focalization (D4, Fig. 11). All internal events were removed based on the division of the verb concepts (I-1). In this result, the verb concept of curse in E3 was deemed an internal type, but is probably objectively perceptible. Although we divided the verb concepts by using the upper categories, division of individual verb concepts is required to provide more adequate rules.

As we showed previously, the basic function of the focalization mechanism (i.e., the regulation of expressed information in a narrative discourse) was achieved by combining the rules of objective perceptible possibility and state-based restriction rules. However, further elaboration of the rules is required to enhance the accuracy of the scope restriction.

\section{Conclusion}

We described the design of a focalization mechanism as a component of INGS. The main function of the mechanism is to restrict the scope of perceived information in a story based on a chosen perspective. We formulated the two types of rules for automatic scope determination. The first concerned a restriction based on the objective perceptible possibility or divisions of story elements into external and internal types. The second concerned a restriction based on the state information in the story. We implemented an experimental focalization system based on this design. The generation examples showed variations of discourses from a story using different types of focalization. In addition, by analyzing the generated discourses, we 
showed that the basic function of the focalization was achieved.

However, further consideration is necessary to construct more effective methods to restrict the perception scope. A future requirement is to divide the verb concepts individually into external and internal types. In addition, although we defined four simple state-based restriction rules, we must consider a more systematic model of relationship between the perception scope and states. Elementary considerations of these issues were described in [22].

This research is an attempt to expand INGS and represents an enhanced approach to expanded literary theory. Our expanded literary theory is applicable to the studies of all generation phases of story, discourse, and surface expression. A broader goal of expanded literary theory for narrative discourse generation is to develop a systematic and computational model of discourse techniques that include the categories of "tense," "mood," and "voice" in Genette's theory. Therefore, future studies should coordinate functional consistency among all discourse techniques, including focalization.

\section{References}

[1] T. Ogata and A. Kanai, (An Introduction to Informatics of Narratology: Towards the Thoughts and Technologies of Narrative Generation), Gakubunsha, 2010.

[2] T. Akimoto and T. Ogata, Macro structure and basic methods in the integrated narrative generation system by introducing narratological knowledge, In: Proceedings of 11 th IEEE International Conference on Cognitive Informatics and Cognitive Computing, pp. 253-262, 2012.

[3] T. Akimoto and T. Ogata, An information design of narratology: The use of three literary theories in a narrative generation system, The International Journal of Visual Design, vol. 7, no. 3, pp. 31-61, 2014.

[4] G. Genette, Discours du Récit, Essai de Méthode, Figures III, Seuil, 1972. (Transl. J.E. Lewin, Narrative Discourse: An Essay in Method, Cornell University Press, 1980.)

[5] T. Ogata, Toward the consistent simulation of narrative discourse based on narratology, In: Proceedings of the 9th International Symposium on Artificial Life and Robotics, vol. 2, pp. 579-584, 2004.
[6] T. Ogata and S. Yamakage, A computational mechanism of the "distance" in narrative: A trial in the expansion of literary theory, In: Proceedings of the 8th World Multiconference on Systemics, Cybernetics and Informatics, vol. 14, pp. 179-184, 2004.

[7] K. Ueda and T. Ogata, A computational modeling of perspective and voice in the narrative rhetoric, In: Proceedings of 18 th Congress of the International Association of Empirical Aesthetics, pp. 480-486, 2004.

[8] T. Akimoto and T. Ogata, A narratological approach for narrative discourse: Implementation and evaluation of the system based on Genette and Jauss, In: Proceedings of the 34th Annual Conference of the Cognitive Science Society, pp. 12721277, 2012.

[9] T. Akimoto and T. Ogata, Towards a discourse mechanism in narrative generation system: Proposal of a system introducing narrative discourse theory and reception theory, Cognitive Studies, vol. 20, no. 4, pp. 396-420, 2013.

[10] T. Ogata, Expanded literary theory: Cognitive/computational expansion of literary theories and narratology, In: Proceedings of 17th Congress of the International Association of Empirical Aesthetics, pp. 163-166, 2002.

[11] T. Ogata, Expanded literary theory for automatic narrative generation, Proceedings of Joint 7th International Conference on Soft Computing and Intelligent Systems and 15th International Symposium on Advanced Intelligent Systems, pp. 1558 1563, 2014.

[12] J. R. Meehan, The Metanovel: Writing Stories by Computer, Garland Publishing, 1980.

[13] P. Gervás, Propp's morphology of the folk tale as a grammar for generation, In: Proceedings of 2013 Workshop on Computational Models of Narrative, pp. 106-122, 2013.

[14] B. Lönneker-Rodman, Narratological knowledge for natural language generation, In: Proceedings of the 10th European Workshop on Natural Language Generation, pp. 91-100, 2005.

[15] N. Montfort, Generating narrative variation in interactive fiction, A Dissertation in Computer and Information Science, University of Pennsylvania, 2007.

[16] A. Jhale and M.R. Young, Cinematic visual discourse: Representation, generation, and evaluation, IEEE Transactions on computational intelligence and A.I. in games, vol. 2, no. 2, pp. 69-81, 2010. 
[17] B. C. Bae, Y. G. Cheong and M. R. Young, Automated story generation with multiple internal focalization, In: Proceedings of 2011 IEEE Conference on Computational Intelligence and Games, pp. 211-218, 2011.

[18] P. Gervás, Stories from games: Content and focalization selection in narrative composition, In: Proceedings of I Spanish Symposium on Entertainment Computing, 2013.

[19] T. Ogata, Building conceptual dictionaries for an integrated narrative generation system, Journal of Robotics, Networking and Artificial Life, vol. 1, no. 4, pp. 270-284, 2015.

[20] T. Akimoto, S. Imabuchi and T. Ogata, A story generation mechanism based on the cooperation of mi- cro/macro story techniques: As a module in the integrated narrative generation system, In: Proceedings of the 12th International Conference on Computer and Information Science, pp. 377-384, 2013.

[21] T. Akimoto, Y. Kurisawa and T. Ogata, A mechanism for managing the progression of events by states in integrated narrative generation system, In: Proceedings of the 2nd International Conference on Engineering and Applied Science, pp. 16051614, 2013.

[22] T. Akimoto and T. Ogata, Towards the focalization mechanism in an integrated narrative generation system, In: Proceedings of the 31st Annual Meeting of the Japanese Cognitive Science Society, pp. 344-353, 2014.

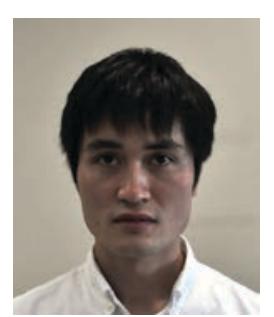

Taisuke Akimoto is a postdoctoral researcher in the Graduate School of Informatics and Engineering, the University of Electro-Communications, Japan. He received his Ph.D. from Iwate Prefectural University in 2014. His research interests include Artificial Intelligence, Informatics, Cognitive Science, etc. Especially, he is interested in automatic narrative generation systems and their applications. He is a member of the Japanese Society for Artificial Intelligence, Japanese Cognitive Science Society, and the Association for Natural Language Processing in Japan.

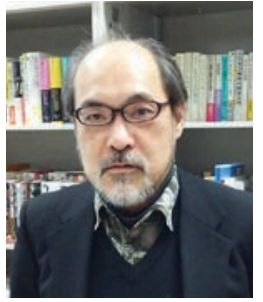

Takashi Ogata received his bachelor of social science in Waseda University in 1983, and then he received his M.Sc. in Tsukuba University in 1992 and his Ph.D. in the University of Tokyo in 1995. He has industrial experience since 1983 at software development companies. Having experienced Associate Professor of the Faculty of Engineering at Yamanashi University since 1997, he is Professor of the Faculty of Software and Information Science at Iwate Prefectural University since 2005. He is interested in an interdisciplinary approach to narrative generation systems based on artificial intelligence and narratology. He received best paper awards (Japanese Society for Artificial Intelligence and Japan Academy of Advertising) (1996) and other academic awards. 